\title{
Elusive trochanteric bursitis relief
}

\section{Bruce Rothschild ${ }^{1}$ (I)}

Received: 25 March 2019 / Accepted: 10 April 2019 / Published online: 19 April 2019

(C) International League of Associations for Rheumatology (ILAR) 2019

An interesting observation draws attention to technique issues. Nissen et al. [1] found that intra-trochanteric injection with betamethasone produced no greater long-term benefit than saline injections for greater trochanteric pain syndrome. One, three, and six month post-injection pain intensity was unaffected by this intervention. Their recommendation that future patients be advised of unlikely long-term benefit would seem reasonable, except for two fundamental methodologic flaws precluding such clinical application of their findings. Betamethasone is water soluble [2] and the terminology trochanteric bursa may be misleading. There are actually four bursa surrounding attachments to the femoral greater trochanter [3]. Those have been variously reported to include the gluteus medius, gluteus minimus, subgluteus medius, and subgluteus minimus tendons $[3,4]$.

There does not appear to be evidence that involvement in individuals with the greater trochanteric pain syndrome is limited to a single bursa. My personal approach is to inject all four of the above-delineated bursa, as I, too, found that injection of a single bursa did not provide long-term relief. The injection procedure is to note presence of pain on positioning the needle in each bursa, prior to the injection of each. That not only confirms the appropriate site for injection but also notes that bursa is inflamed. My observation is that all four bursa are inflamed, or at least sources of clinical symptoms, in almost all individuals with greater trochanteric pain syndrome.

Returning the first point, it is unclear that water-soluble, highly diffusible agents remain in sufficient quantity (levels) in the injected areas to provide long-term relief or even to allow healing of the inflammatory process. This concern for bursal injections is predicated upon noted lack of efficacy of most water soluble, contrasted with water-insoluble corticosteroids efficacy for knee joint injections [5]. It should be noted that joint (as opposed to bursa) steroid injections are no longer favored because of the damage to joint cartilage [6], not an issue in bursal closed spaces. My choice of injectable is the water-insoluble/depot drug, triamcinolone, assuring that all inflamed bursa are injected.

\section{Compliance with ethical standards}

Disclosures None

\section{References}

1. Nissen MJ, Brulhart L, Faundez A, Finckh A, Couvoisier DS, Genevay S (2019) Glucocorticoid injections for greater trochanteric pain syndrome: a randomized double-blind placebo-controlled (GLUTEAL) trial. Clin Rheumatol 38:647-655

2. MacMahon PJ, Eustace SJ, Kavanagh EC (2009) Injectable corticosteroid and local anesthetic preparations. Radiology 252:647-661

3. Williams BS, Cohen SF (2009) Greater trochanteric pain syndrome: a review of anatomy, diagnosis and treatment. Anesth Analg 108: 1662-1670

4. Dunn T, Heller CA, McCarthy SW, Dos Remedios C (2003) Anatomical study of the "trochanteric bursae". Clin Anat 16:233-240

5. Cole BJ, Schumacher HR Jr (2005) Injectable corticosteroids in modern practice. J Am Acad Orthop Surg 13:37-46

6. McAlindon T, LaValley M, Harvey W, Price LL, Driban JB, Zhang M, Ward RJ (2017) Effect of intra-articular triamcinolone vs saline on knee cartilage volume and pain in patients with knee osteoarthritis: a randomized clinical trial. JAMA 317:1967-1975

Publisher's note Springer Nature remains neutral with regard to jurisdictional claims in published maps and institutional affiliations.

Bruce Rothschild

spondylair@gmail.com

Indiana University, Carnegie Museum, 4400 Forbes Ave, Pittsburgh, PA 15213, USA 